\title{
Rheological behavior and thermal properties of pitch/poly(vinyl chloride) blends
}

\author{
S.R. Hlatshwayo, W.W. Focke*, S. Ramjee, B. Rand, and N. Manyala
}

SARChI Chair in Carbon Technology and Materials, Institute of Applied Materials, Departments of Chemical Engineering and of Department of Physics, University of Pretoria, Private Bag X20, Hatfield 0028, South Africa

\begin{abstract}
The effect of adding poly(vinyl chloride) (PVC) and coke filler on the rheological behavior and thermal properties of a coal tar pitch was investigated with a view to developing an appropriate viscoelastic binder for the injection molding of graphite components. Dynamic mechanical analysis revealed that the pitch formed compatible blends with PVC featuring a single glass transition temperature (Tg) intermediate to the two parent Tg's. Adding PVC to the pitch increased melt viscosity substantially and resulted in strong shear thinning behavior at high PVC addition levels. Adding coke powder as filler increased the melt viscosity even further and enhanced shear thinning trends. Pyrolysis conducted in a nitrogen atmosphere revealed interactions between the PVC and pitch degradation pathways: the blends underwent significant thermal decomposition at lower temperatures but showed enhanced carbon yields at high temperatures. Pyrolytic carbon yield at $1000{ }^{\circ} \mathrm{C}$ was further improved by a heat treatment (temperature scanned to $400{ }^{\circ} \mathrm{C}$ ) in air or oxygen. However, carbon yield decreased with addition of PVC. In addition, the degree of ordering attained following a one hour heat treatment at $2400{ }^{\circ} \mathrm{C}$ also decreased with increasing PVC content.
\end{abstract}

* Corresponding author: Tel: +27 12420 3728. Fax: +27 12420 2516. E-mail address: walter.focke@up.ac.za (W.W. Focke) 


\section{Introduction}

Coal tar pitch is a highly aromatic binder and impregnation resin in the production of bulk carbon materials and graphite fiber composites [1]. The rheological behavior and filler wetting properties of the pitch are important in this and other applications [2]. The ultimate aim of our research is to develop carbon precursors suitable for near net shape fabrication of carbon components by injection molding or extrusion processes. While a low melt viscosity is an advantage for impregnation applications, it is a distinct drawback for extrusion processes. Adding small amounts of a high polymer such as poly(vinyl chloride) (PVC) could significantly improve processability in such applications by imparting a degree of elasticity to the mixture.

At low temperatures pitch tends to behave like a Bingham plastic with a definite yield stress [3]. At temperatures well above the softening point isotropic pitches exhibit Newtonian viscosity behavior [4]. However, non-Newtonian fluid behavior is observed with anisotropic pitches, e.g. those containing mesophase [5]. In binder applications the pitch forms the continuum fluid in the mixture; consequently the viscoelastic properties of the system are governed by those of the pitch. However, the rheological properties of a dispersion also depend on the filler volume fraction [6], the shape and the size distribution of the particles as well as their propensity to agglomerate [7].

Blending poly(vinyl chloride) (PVC) into the pitch can impart desirable attributes to carbon precursors for nuclear graphite applications. The presence of halogens during high temperature heat treatment facilitates removal of metal impurities as volatile halides [8]. While pyrolysis of PVC yields isotropic carbons [9], blends of coal tar pitch and PVC are graphitizable [10]. Addition of PVC to aromatic pitches improves the carbon yield [11]. This increase is attributed to the pitch components reacting with PVC to form higher molecular weight species. 
The objective of this study was to characterize the rheological and thermochemical properties of an isotropic coal tar binder pitch, its blends with PVC as well as coke-filled compounds. It is hoped that this may assist future development of appropriate formulations for extrusion and injection molding applications. Typical shear rates experienced in these conventional polymer processes are $10^{2}-10^{3} \mathrm{~s}^{-1}$ for extrusion and $10^{3}-10^{4} \mathrm{~s}^{-1}$ for injection molding.

\section{Experimental}

\subsection{Materials}

The coal tar pitch (110MP) obtained from Arcelor-Mittal had a softening point of $110{ }^{\circ} \mathrm{C}$ and a coke yield of ca. $40 \mathrm{wt} \%$. The Quinoline Insolubles (QI) and Toluene Insolubles (TI) were 9 wt. $\%$ and 34 wt.\% respectively. The Aromaticity Index was 0.53 and the $\mathrm{C} / \mathrm{H}$ atomic ratio was 1.8. The calcined medium temperature coal tar pitch coke (CMTPC), produced at Sasol by coking at $1400^{\circ} \mathrm{C}$, was employed as filler. This coke was hammer milled into a fine powder $\left(\mathrm{d}_{10}=1.8 ; \mathrm{d}_{50} 8.4 \mu \mathrm{m}\right.$, and $\left.\mathrm{d}_{100}=31.9 \mu \mathrm{m}\right)$. Sasol Polymers supplied the suspension grade poly(vinyl chloride) (PVC S5718). It was a free flowing powder with a K-value of 56 58. The PVC was formulated into a heat stabilized compound comprising $92.5 \mathrm{wt} . \% \mathrm{PVC}, 5$ wt.\% Epicote 1002 and 2.5 wt.\% Ecostab 6300 organic stabilizer (supplied by SunAce). All compositions reported here refer to the content of this PVC compound in the mixture.

\subsection{Compounding}

The pitch/PVC blends and their coke filled versions were compounded on a $28 \mathrm{~mm}$ corotating intermeshing twin screw laboratory extruder $(\mathrm{L} / \mathrm{D}=16)$ at a screw speed of $135-219$ rpm. The screw design comprised intermeshing kneader elements with a forward transport action. The processing temperature profile ranging from $90^{\circ} \mathrm{C}$ to $180^{\circ} \mathrm{C}$ but compositions 
with high pitch content were compounded using a $90{ }^{\circ} \mathrm{C}$ to $130{ }^{\circ} \mathrm{C}$ profile. The extruded strand was granulated and injection molded into test bars on an Engel 3040 injection-molding machine with a clamping force $350 \mathrm{kN}$. Barrel temperatures varied from 120 to $180{ }^{\circ} \mathrm{C}$ for all samples. The injection and holding pressures were 180 bar and 80 bar respectively.

\subsection{Heat treatments}

The injection molded samples were coked at $1000{ }^{\circ} \mathrm{C}$ for $1 \mathrm{~h}$ in a $\mathrm{N}_{2}$ atmosphere. They were subsequently "graphitized" for $1 \mathrm{~h}$ at $2400{ }^{\circ} \mathrm{C}$ in a stream of helium. In both heat treatments the furnace temperature was raised at $1 \mathrm{~K} \cdot \mathrm{min}^{-1}$ to the final soak temperature. Afterwards the samples were allowed to cool slowly and freely down to ambient temperature.

\subsection{Characterization}

The samples were characterized as follows. Particle size distribution and BET surface area were determined using a Malvern Mastersizer Hydro 2000MY instrument and a Micromeritics Flowsorb II 2300 instrument respectively. The ash composition of the coke was checked using a wavelength-dispersive X-ray Fluorescence (XRF) spectrometer (ARL $9400 \mathrm{XP}+\mathrm{XRF})$. The coke powder was ground in a tungsten carbide milling vessel and roasted at $1000{ }^{\circ} \mathrm{C}$ for loss on ignition (LOI) determination. Samples were pelletized using ethyl cellulose as binder.

\subsubsection{Raman spectroscopy}

The Raman spectra were recorded with a T64000 series II triple spectrometer system from HORIBA Scientific, Jobin Yvon Technology using the $514.3 \mathrm{~nm}$ laser line of a coherent Innova ${ }^{\circledR} 70 \mathrm{Ar}^{+}$laser with a resolution of $2 \mathrm{~cm}^{-1}$ in the range 1200 to $1700 \mathrm{~cm}^{-1}$. The samples were recorded in a backscattering configuration with an Olympus microscope attached to the 
instrument (using a LD 50x objective). The laser power was set at of $6 \mathrm{~mW}$ and a nitrogencooled CCD detector was used. The accumulation time was $120 \mathrm{~s}$ and the spectra were baseline corrected with using LabSpec software.

\subsubsection{Optical microscopy (OM)}

The microstructure of the blends in the injection molded samples was studied with optical microscopy (OM) under polarized light using a Leica DM 2500M microscope. Samples mounted in an epoxy resin were polished with a Buehler Alpha 2 speed polisher. The polishing was done under a continuous flow of water for one minute each on a succession of increasingly finer silicon carbide abrasive papers $(400,600,1200$ grit). Finally the sample polishing was completed using first a $1 \mu \mathrm{m}$ and then a $0.05 \mu \mathrm{m}$ Buehler MetaDi polishing suspension for 3 and 2 minutes, respectively.

\subsubsection{Scanning Electron Microscopy (SEM)}

SEM images were obtained using an ultrahigh resolution field emission SEM (HR FEGSEM Zeiss Ultra Plus 55) with an InLens detector at acceleration voltages of $3 \mathrm{kV}$ to ensure maximum resolution of surface detail.

\subsubsection{X-Ray Diffraction (XRD)}

XRD diffraction patterns were recorded using a Bruker D8 Advance powder diffractometer fitted with a Lynx eye detector. Measurements were performed in the $2 \theta$ range $15-120^{\circ}$ with a $0.04^{\circ}$ step size and a counting time of $0.2 \mathrm{~s}$. The interlayer spacing, $\mathrm{d}_{002}$, calculated using the Bragg equation, was used as an indicator for the extent of ordering. 


\subsubsection{Rheometry}

Melt flow viscosity was measured using a Göttfert High Pressure Capillary Rheograph 2000 rheometer. The capillary die was $30 \mathrm{~mm}$ long. The die had a $180^{\circ}$ entrance angle and the diameter of the capillary was $1 \mathrm{~mm}$. The rheometer was equipped with a 100 bar pressure sensor and capable of applying shear rates in the range $10-20000 \mathrm{~s}^{-1}$. Measurements on the PVC compound and its blends with pitch were done at $160{ }^{\circ} \mathrm{C}$.

Since capillary rheometer data showed considerable scatter, pitch viscosity determinations were instead done on an Anton Paar Physica MCR301 rheometer fitted with a convection hood (CTD600). Data were obtained in steady mode at shear rates between 0.1 and $1000 \mathrm{~s}^{-1}$ using a $20 \mathrm{~mm}$ parallel plate measuring system. Nitrogen gas was used to maintain an inert atmosphere and the tests were done at the temperatures ranging from $80{ }^{\circ} \mathrm{C}$ to $120^{\circ} \mathrm{C}$.

\subsubsection{Dynamic mechanical analysis (DMA)}

DMA data were recorded on a Perkin Elmer DMA 8000 using material pockets [14]. The latter are stainless steel envelopes that hold powdered samples so that they can be mounted in the DMA instrument. Measurements were done in the single cantilever bending mode. The temperature ramp rate was $2 \mathrm{~K} \cdot \mathrm{min}^{-1}$ and a frequency of $5 \mathrm{~Hz}$ was employed for all measurements.

\subsubsection{Thermogravimetry (TG)}

A Mettler Toledo A851 simultaneous TGA/SDTA machine was used for thermogravimetric analysis. Powder samples (ca. $20 \mathrm{mg}$ ) were placed in open $70 \mu \mathrm{L}$ alumina pan and heated from $25^{\circ} \mathrm{C}$ to $1000{ }^{\circ} \mathrm{C}$ at a scan rate of $10 \mathrm{~K} \cdot \mathrm{min}^{-1}$ in air or nitrogen. 
In addition, for TG crosslinking experiments, samples were first heated at a scan rate of $10 \mathrm{~K} \cdot \mathrm{min}^{-1}$ from $25{ }^{\circ} \mathrm{C}$ up to $400{ }^{\circ} \mathrm{C}$ in either air or oxygen flowing at $50 \mathrm{~mL} \cdot \mathrm{min}^{-1}$. On reaching this temperature, the samples were rapidly cooled back to $25^{\circ} \mathrm{C}$ at a scan rate of $100 \mathrm{~K} \cdot \mathrm{min}^{-1}$. The atmosphere was switched back to a $50 \mathrm{~mL}$ flow of nitrogen and the samples heated at $10 \mathrm{~K} \cdot \mathrm{min}^{-1}$ to $1000{ }^{\circ} \mathrm{C}$.

\section{Results and Discussion}

The ash content of the coke was only $0.13 \mathrm{wt} . \%$. The dominant elements present in the ash were iron, silicon, sulfur, aluminum, calcium and magnesium.

\subsection{Melt rheology}

The effects of shear rate and temperature on the viscosity of the pitch were determined with the parallel plate rheometer. The shear rate was varied from $0.01 \mathrm{~s}^{-1}$ to $100 \mathrm{~s}^{-1}$ at temperatures ranging from $80{ }^{\circ} \mathrm{C}$ to $120^{\circ} \mathrm{C}$ in $10{ }^{\circ} \mathrm{C}$ intervals. The flow curve for each temperature was approximately horizontal, i.e. almost independent of shear rate. This indicates that the pitch behaved like a Newtonian fluid at moderate shear rates and temperatures above $90{ }^{\circ} \mathrm{C}$. The flow curve obtained at $80^{\circ} \mathrm{C}$ showed a slight downward trend, i.e. shear thinning. Such behavior was also indicated at the higher shear rates in the flow curves obtained at the other temperatures. Nevertheless, temperature was by far the dominant factor. Viscosity changed by more than three orders of magnitude in the temperature range $80{ }^{\circ} \mathrm{C}$ to $120^{\circ} \mathrm{C}$. In this range the effect of temperature on the Newtonian viscosity showed an Arrhenius temperature dependence with an activation energy of ca. $E=219 \mathrm{~kJ} \cdot \mathrm{mol}^{-1} \cdot \mathrm{K}^{-1}$ and a pre-exponential factor of $1.41 \times 10^{30}$. Extrapolation this trend predicted a zero shear viscosity of $0.38 \mathrm{~Pa} . \mathrm{s}$ at $160{ }^{\circ} \mathrm{C}$. This value is plotted as a dashed horizontal line in Fig. 1. 
Fig. 1 shows experimental flow curves for pitch/PVC blends at $160{ }^{\circ} \mathrm{C}$. The 10 wt. $\%$ PVC blend featured a nearly shear independent viscosity of ca. 3.7 Pa.s or about an order of magnitude higher than the value estimated for pitch at this temperature. All other samples tested exhibited non-Newtonian (shear thinning) behavior. The tendency for shear thinning became more pronounced with increasing PVC content. Table 1 reports selected parameter values for the power law viscosity model. Perusal of these results indicates that, with increasing PVC content, the consistency index $(K)$ increased and the flow behavior index $(n)$ decreased. Fig. 1 further shows that the composition dependence is highly non-linear with the 50 wt.\% PVC compound showing the highest viscosity at high shear rates.

The flow curves for the two coke-filled compounds shown in Fig. 2 also show powerlaw shear thinning behavior in the range of shear rates reported here. Both compounds contained $50 \mathrm{wt} . \%$ coke but differed with respect to the PVC content of the binder phase. These values were $10 \mathrm{wt} . \%$ and $20 \mathrm{wt} . \%$, respectively on a filler-free basis. Recall that Newtonian behavior was noted for the former blend in the absence of filler. However, in the presence of filler, a strong shear thinning trend is noted. This change in behavior can be explained by assuming a cohesive nature for the coke particles [7]. If the particles have a high propensity to stick to one another, they readily form agglomerates that trap fluid within their interstices. This increases the apparent viscosity of the suspension. Applying shear tends to break down the agglomerates causing particles to become individually dispersed in the liquid medium. The interstitial fluid is released and the apparent viscosity is reduced. The filled compound based on the $20 \mathrm{wt} . \%$ PVC binder fluid featured a viscosity that was almost one order of magnitude higher. In practice it was found that this compound was very difficult to injection mold. 


\subsection{Solid state morphology}

Complex, seemingly co-continuous patterns, comprising domains with different color intensities, are revealed when polished samples of injection molded pitch/PVC blends were viewed under polarizing light. Fig. 3 shows micrographs for two blends containing 25 wt.\% and $50 \mathrm{wt} . \%$ PVC, respectively. The dark spots in both pictures are spherical cavities and this shows that the as-molded materials already featured some porosity. It is not clear from the optical microscopy whether the fringed patterns simply reflect difference in local orientations or whether they indicate the presence of two immiscible phases with significantly different composition, possibly caused by incomplete homogenization during mixing. The miscibility of blends of amorphous materials is often inferred from modulus and tan $\delta$ data obtained with dynamic thermal analysis (DMA). Immiscible blends show two tan $\delta$ peaks and a stepwise change in the modulus commensurate with the different properties of the two phases present [16]. A completely miscible blend shows a single Tg that varies with composition according to the Fox equation [16]:

$\frac{1}{\operatorname{Tg}}=\frac{w_{1}}{\operatorname{Tg}_{1}}+\frac{w_{2}}{\operatorname{Tg}_{2}}$

where $\mathrm{Tg}$ and $\mathrm{Tg}_{i}$ are the glass transition of the miscible blend and the parent phase, respectively, while $w_{i}$ represents the mass fraction of phase $i$. Fig. 4 shows tan $\delta$ plots for the neat pitch, PVC and their 1:1 blend. Tg values were taken as the temperatures corresponding to maxima in the $\tan \delta$ curves. In this context the pitch has a lower glass transition temperature $\left(74.6^{\circ} \mathrm{C}\right)$ than the $\mathrm{PVC}\left(92.8^{\circ} \mathrm{C}\right)$ while the blend showed an intermediate glass transition temperature $\left(84^{\circ} \mathrm{C}\right)$. The effect of composition variations on the blend $\mathrm{Tg}$ corresponded fairly well with the predictions of equation (2). This agreement with the Fox relationship points to a single phase nature for the pitch/PVC blends. 


\subsection{Thermal behavior}

Fig. 5 shows the pyrolysis behavior of the pitch, the PVC and the coke in an $\mathrm{N}_{2}$ atmosphere. The coke is very stable in this inert gas and the mass loss to $900{ }^{\circ} \mathrm{C}$ only amounts to $2.5 \%$. The pitch started to lose mass at a lower temperature than PVC but this onset may represent volatilization of lower molar mass species rather than thermal degradation. The pitch degraded via a single mass loss step that reached completion at ca. $550{ }^{\circ} \mathrm{C}$ with a char yield of ca. $38 \%$ at $900{ }^{\circ} \mathrm{C}$. The PVC apparently degraded via a two-step process. The first step is primarily due to dehydrochlorination reactions. It commenced above $200{ }^{\circ} \mathrm{C}$ and reached a plateau between ca. $350{ }^{\circ} \mathrm{C}$ and $400{ }^{\circ} \mathrm{C}$. The second step reached completion at ca. $500{ }^{\circ} \mathrm{C}$ and the char yield was about $10 \mathrm{wt} . \%$ at $900^{\circ} \mathrm{C}$. Pitch/PVC blends showed similar two-step thermal degradation. However, there is evidence of mutual destabilization as, for the blends, much of the mass loss in the first step occurred at a lower temperature $\left(<300{ }^{\circ} \mathrm{C}\right)$. The char yields obtained for the blends exceeded that calculated from the linear blending rule. These observations indicate that the degradation of the two parent materials did not proceed independently in the mixtures. Rather, there was significant interaction with greater mass loss observed in the beginning but with enhanced carbon yield at the completion of the pyrolysis.

Fig. 6 shows the burn off behavior of the pitch, the PVC and the coke in an air atmosphere. In this reactive gas at least three mass loss steps for the PVC and four for the pitch were in evidence. The first step in the PVC still involved mostly dehydrochlorination. It leads to a mass loss plateau that ended abruptly at ca. $410^{\circ} \mathrm{C}$. A distinct plateau located between $410{ }^{\circ} \mathrm{C}$ and $500{ }^{\circ} \mathrm{C}$ was observed for the pitch sample. This plateau occurred between the second and third mass loss steps. For comparison, the mass loss curve obtained for the pitch in $\mathrm{N}_{2}$ is also shown. Clearly, and initially counter intuitively, the mass loss of pitch in air was less than the mass loss observed in nitrogen up to temperatures of ca. $700{ }^{\circ} \mathrm{C}$ ! This unexpected behavior can be rationalized as follows: Oxygen is a known crosslinking 
agent for carbon and graphite precursors. It is conceivable that similar reactions occur in pitch exposed to oxygen at elevated temperatures. Larger molecules with a reduced vapor pressure are formed at the beginning of the oxidation cycle. This limits mass loss due to vaporization in the early stages of the heat treatment. This principle can be exploited to improve the system's char yield under pyrolysis conditions. Towards this end crosslinking experiment were conducted in which the samples were first heated to $400{ }^{\circ} \mathrm{C}$ in the reactive atmosphere (air or oxygen) and then pyrolyzed in nitrogen. The results are presented in Fig. 7. They confirm the beneficial effect of oxygen exposure during the early stages of pyrolysis. Presently the best results were obtained using an oxygen atmosphere rather than air. However, it is possible that oxygen and air atmospheres will deliver similar performance under optimized time-temperature programs. It is quite possible that even higher char yields can be obtained by optimizing the temperature program.

Fig. 8 shows the effect of a $2400{ }^{\circ} \mathrm{C}$ heat treatment on the Raman spectra for a 50 wt.\% pitch/PVC blend. The Raman spectra for the other "graphitized" samples were very similar. Table 2 reports the $I_{D} / I_{G}$ peak intensity ratios for neat, electron beam irradiated and "graphitized" pitch/PVC samples. Lower values for this ratio indicate increased ordering [17].

Fig. 9 shows the effects of the $1000{ }^{\circ} \mathrm{C}$ and $2400{ }^{\circ} \mathrm{C}$ heat treatments on the X-ray diffractograms for the coke/pitch/PVC 50/45/5 compound. The sharp peaks indicate that considerable ordering had taken place. Table 2 summarizes d-spacing estimates obtained from XRD for the pitch/PVC blends. The highest degree of ordering was achieved with the neat pitch and the lowest with the PVC. Adding PVC to the pitch tended to lower the degree of ordering that was achieved. 
The morphology of selected samples that were heat treated at $2400{ }^{\circ} \mathrm{C}$ is shown in Fig. 10. In all cases a high degree of porosity is evident with the matrix characterized by a distinct flake-like morphology. The latter is most conspicuous in the pitch sample.

\section{Conclusions}

Coal tar pitch 110MP forms completely miscible blends with PVC. The blend Tg values closely matched the mass fraction weighted harmonic means of the parent $\mathrm{Tg}$ values in accordance with the predictions of the Fox equation. The pitch behaves like a Newtonian fluid at temperatures well above its Tg but some shear thinning was observed at very high shear rates. Adding PVC increased the melt viscosity dramatically. At a $10 \%$ addition of PVC the flow behavior was roughly Newtonian but with 50 wt. \% coke as filler, strong shear thinning behavior developed. This was attributed to shear-induced breakdown of coke particle agglomerates. Strong shear thinning behavior was also observed in blends that contained more than 10 wt. \% PVC. The composition dependence was highly nonlinear with the 50 wt. \% PVC blend showing the highest viscosity at high shear rates.

The carbon yield of the pitch/PVC blends decreased with increasing PVC content. It was significantly improved by a short heat treatment at $400{ }^{\circ} \mathrm{C}$ in air or oxygen. This was attributed to oxygen-mediated crosslinking reactions.

Raman and XRD results indicate that significant ordering occurred when the blends and filled compounds were heat treated at $2400{ }^{\circ} \mathrm{C}$ for $1 \mathrm{~h}$. Using XRD-determined d-spacing values as measure, pitch showed a greater degree of ordering than PVC. The pitch/PVC blends featured intermediate degrees of ordering but the ordering achieved with a $50 \%$ cokefilled compound was comparable to that of the neat pitch. SEM analysis of these "graphitized" samples revealed a flake-like microstructure for all samples but it was 
especially well developed in the "graphitized" pitch. SEM also revealed the development of considerable porosity in molded specimens.

\section{Acknowledgements}

This work is based upon research supported by the PBMR and the South African Research Chairs Initiative of the Department of Science and Technology (DST) and the National Research Foundation (NRF). Any opinion, findings and conclusions or recommendations expressed in this material are those of the authors and therefore the PBMR, NRF ad DST do not accept any liability with regard thereto. The authors express their appreciation to Elke Kamper, Daniel Heidenreich and Hans-Joachim Radusch from the Martin Luther University Halle-Wittenberg for assistance with capillary viscometry and optical microscopy. Lastly authors want to thank Joseph Sebekedi and Rainer Schumacher for help with compounding trials.

\section{References}

[1] Menéndez R, Bermejo J, Figueiras A. Tar and pitch: composition and application. In: Marsh H, Rodríguez-Reinoso F. Sciences of Carbon Materials, Alicante; Publicaciones Universidad de Alicante; 2000 p.173-95.

[2] Rand B. Pitch precursors for advanced carbon materials - rheological aspects. Fuel 1987; 66(11):1491-503.

[3] Bhatia G, Aggarwal RK, Chari SS, Jain GC. Rheological characteristics of coal tar and petroleum pitches with and without additives. Carbon 1977;15(4):219-23.

[4] Sakai M. Viscoelastic properties of a pitch and coke-pitch disperse system. Carbon 1979;17(2):139-44. 
[5] Blanco C, Fleurot O, Menendez R, Santamaria R, Bermejo J, Edie D. Contribution of the isotropic phase to the rheology of partially anisotropic coal-tar pitches. Carbon 1999;37(7):1059-64.

[6] Nutz M, Furdin G, Medjahdi G, Marêché JF, Moreau M. Rheological properties of coal tar pitches containing micronic graphite powders. Carbon, 1997;35(7):1023-9.

[7] Focke WW, Molefe D, Labuschagne FJW and Ramjee S. The influence of stearic acid coating on the properties of magnesium hydroxide, hydromagnesite and hydrotalcite powders. J Mat Sci 2009;44(22):6100-9.

[8] Fagan AW. Packaging and purifying graphite. US Patent 3848739, 1974.

[9] Otani S. On the carbon fiber from the molten pyrolysis products. Carbon 1965;3(1):31-4.

[10] Cornford C, Marsh H. Quantitative optical reflectivity studies of graphitizable carbons from coal-tar pitch, polyvinylchloride and acenaphthylene. Fourth International Carbon Conference. (Baden-Baden, Germany): 1976 and Carbon, 1976;14(5):298.

[11] Yamashita Y, Ouchi K. Modification of pitches by poly (vinylidene chloride) and poly (vinyl chloride). Fuel 1974;53(1):3-7.

[12] Dorschner H, Lappan U, Lunkwitz K. Electron beam facility in polymer research: radiation induced functionalization of polytetrafluoroethylene. Nucl Instr Meth Phys Res B 1998;139(1-4):495-501.

[13] Maire J and Mering J. Graphitization of soft carbons. In: Walker Jr. PL, editor. Chemistry and Physics of Carbon, vol 6, New York; Marcel Dekker; 1970 p.125. [14] Mahlin D, Wood J, Hawkins N, Mahey J, Royal PG. A novel powder sample holder for the determination of glass transition temperatures by DMA. Int J Pharm 2009;371(12):120-5.

[15] Carreau PJ. Rheological equations from molecular network theories. Trans Soc Rheol 1972;16(1):99-127. 
[16] Fox TG. Influence of diluent and copolymer composition on the glass temperature of a polymer system. Bull Am Phys Soc 1956;1:123.

[17] Tuinstra F, Koeng JL. Raman spectrum of graphite. J Chem Phys 1970;53(3):1126-30.

Table 1. Consistency index $(K)$ and flow behavior index $(n)$ for selected compounds

\begin{tabular}{ccccc}
\hline & Composition [wt.\%] & & $n$ & $K$ \\
Pitch & PVC & Coke & {$[-]$} & {$\left[\right.$ [kPa.s $\left.^{n}\right]$} \\
\hline 75 & 25 & - & 0.553 & 1.11 \\
50 & 50 & - & 0.219 & 54.6 \\
25 & 75 & - & $\approx 0$ & 81.5 \\
- & 100 & - & $\approx 0$ & 117.1 \\
45 & 5 & 50 & 0.489 & 5.28 \\
40 & 10 & 50 & 0.352 & 45.7 \\
\hline
\end{tabular}

Table 2. Raman and XRD results for pitch/PVC blends as well and a coke-filled sample

\begin{tabular}{c|cc|c}
\hline Coke/pitch/PVC & \multicolumn{2}{|c|}{ Raman $\mathbf{I}_{\mathbf{D}} / \mathbf{I}_{\mathbf{G}}[-]$} & XRD ("graphitized") \\
[wt.\%] & Neat & “Graphitized" & d-spacing [nm] \\
\hline $0 / 100 / 0$ & 0.606 & 0.151 & 0.339 \\
$0 / 75 / 25$ & 0.524 & 0.212 & 0.341 \\
$0 / 50 / 50$ & 0.692 & 0.154 & 0.340 \\
$0 / 25 / 75$ & 0.956 & 0.169 & 0.341 \\
$0 / 0 / 100$ & 0.929 & 0.171 & 0.342 \\
$50 / 45 / 5$ & 0.769 & 0.188 & 0.339 \\
\hline
\end{tabular}




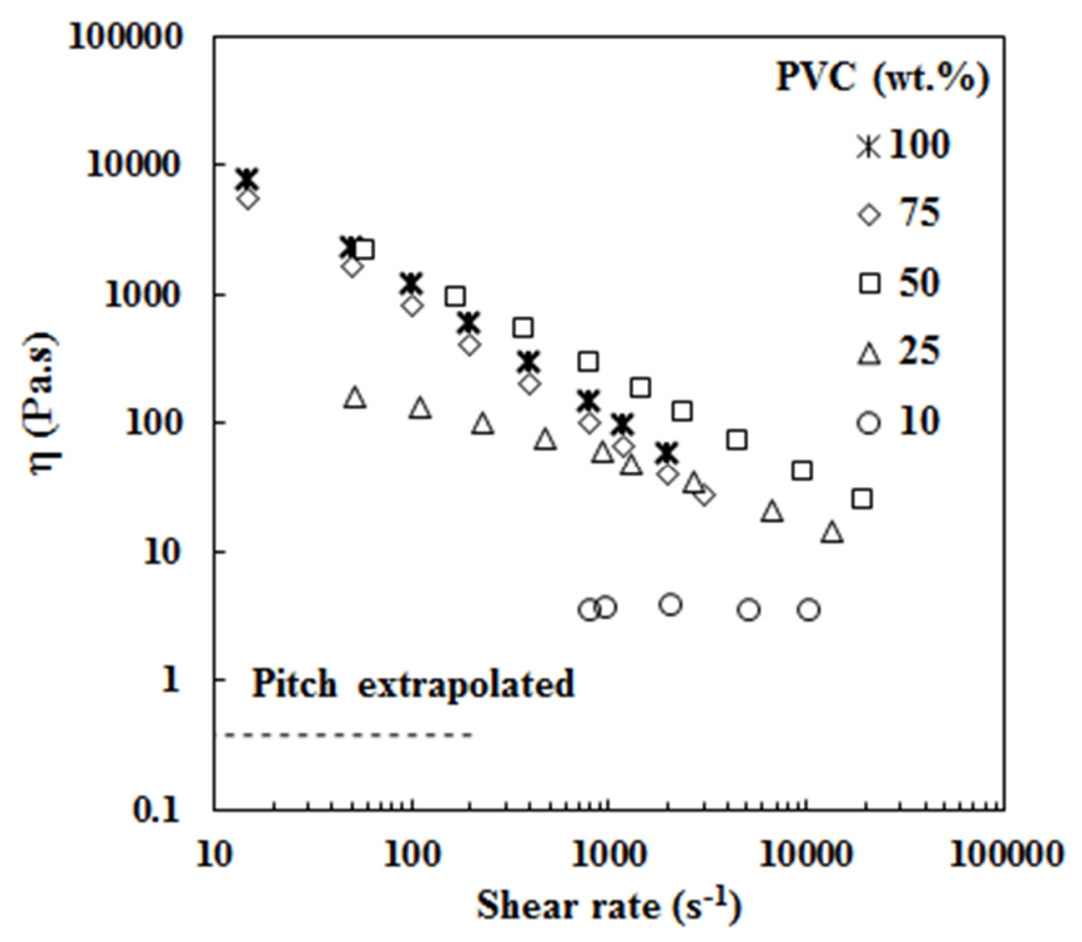

Fig. 1. Capillary rheometer flow curves for pitch/PVC blends measured at $160{ }^{\circ} \mathrm{C}$. The broken line represents an estimate of the neat pitch viscosity based on an extrapolation of the parallel plate rheometer data.

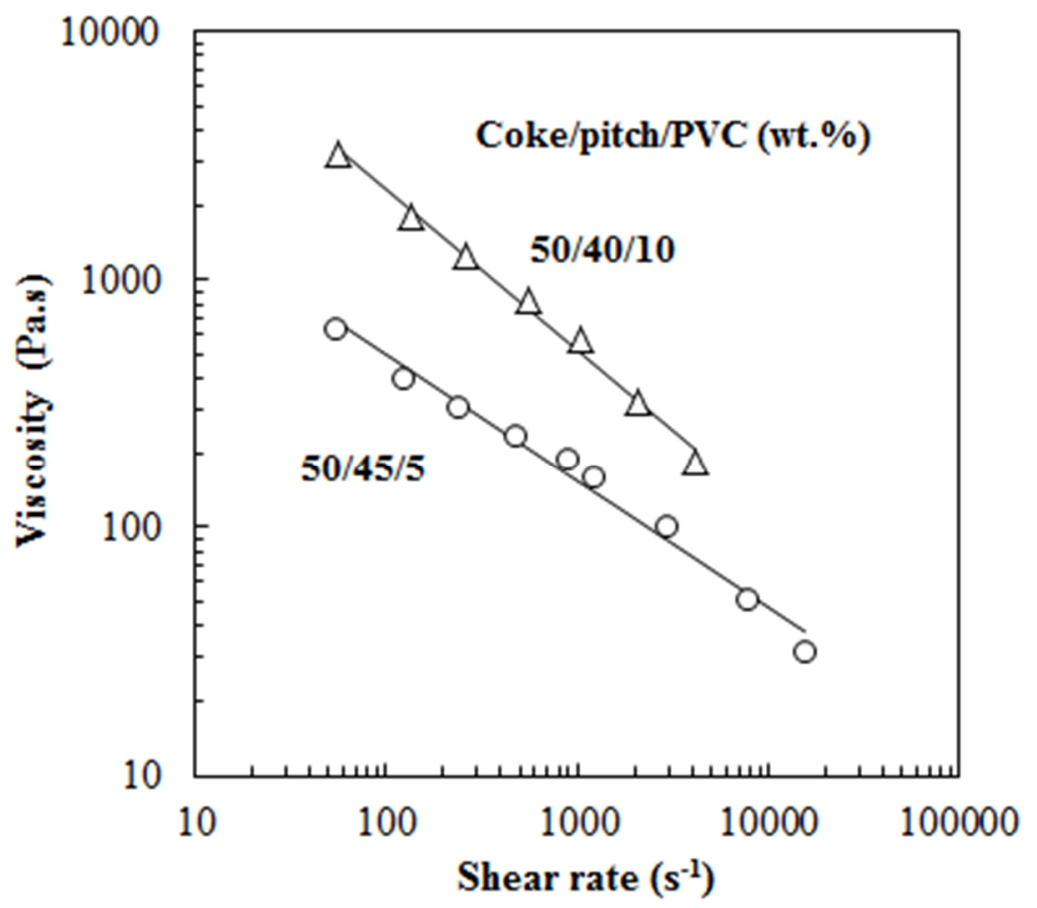

Fig. 2. The effect of shear rate on the capillary viscosity of coke filled pitch/PVC blends at $160{ }^{\circ} \mathrm{C}$. 


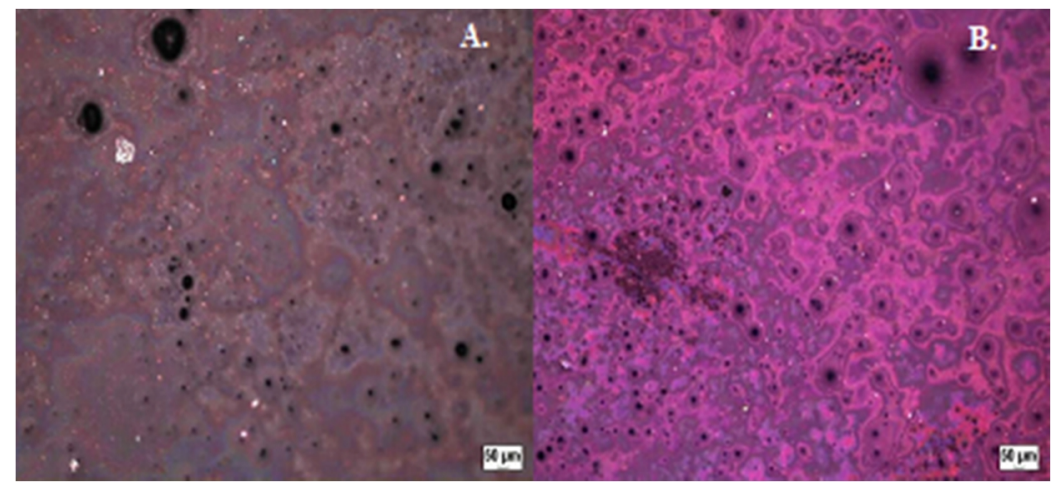

Fig. 3. Optical micrographs with a polarizing filter of injection molded Pitch/PVC blends taken at 50X magnification. A. 25 wt.\% PVC; B. 50 wt.\% PVC.

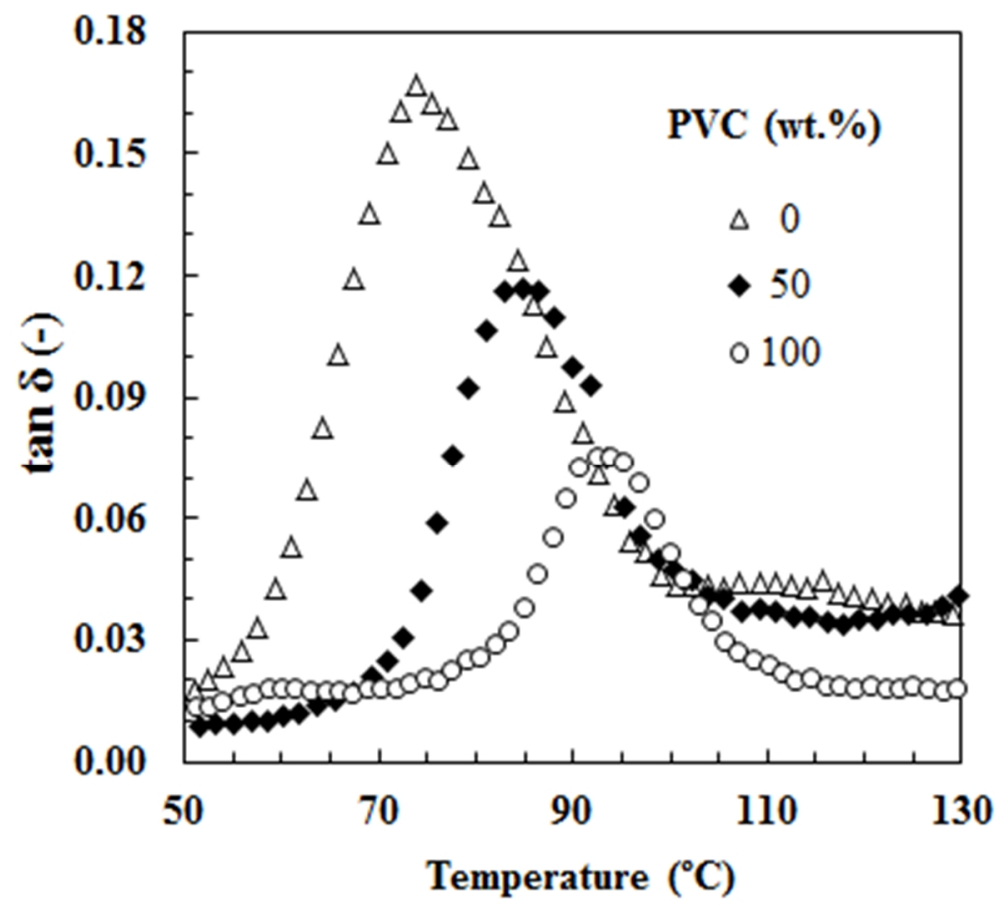

Fig. 4. DMA $\tan \delta$ measured at $5 \mathrm{~Hz}$ for selected powdered Pitch/PVC blends using the pocket technique. 


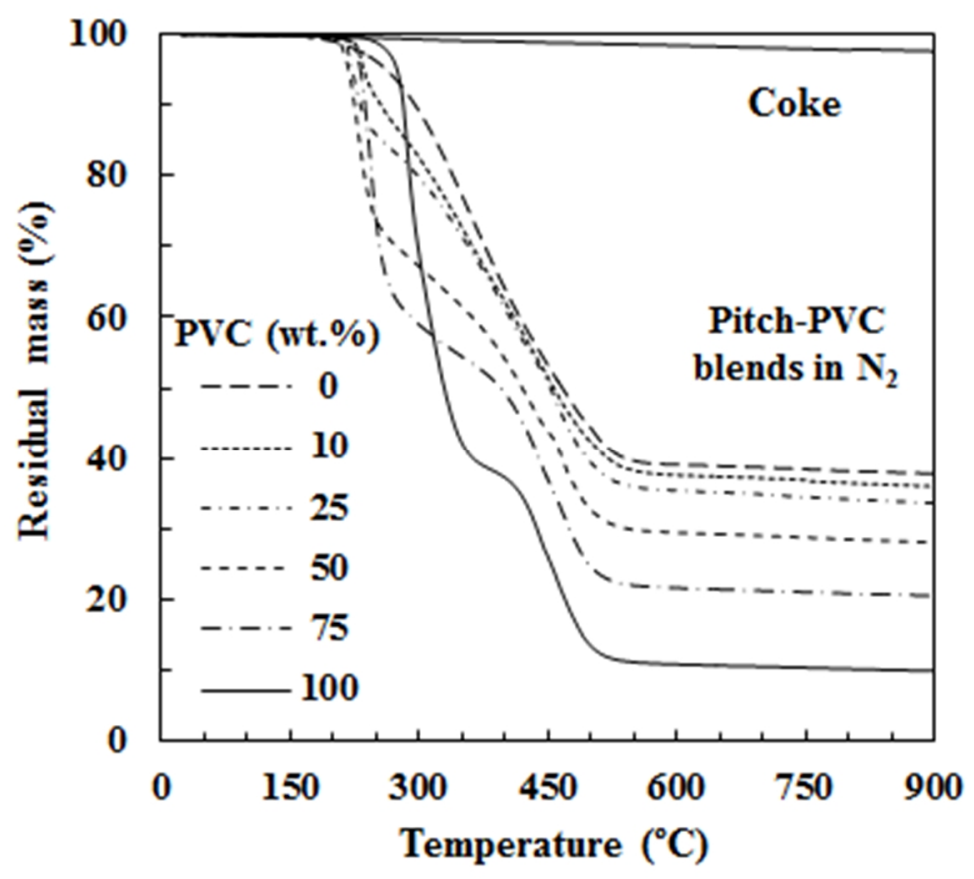

Fig. 5. Pyrolysis behavior of the coke, pitch, $\mathrm{PVC}$ and blends of the latter two in a $\mathrm{N}_{2}$ atmosphere.

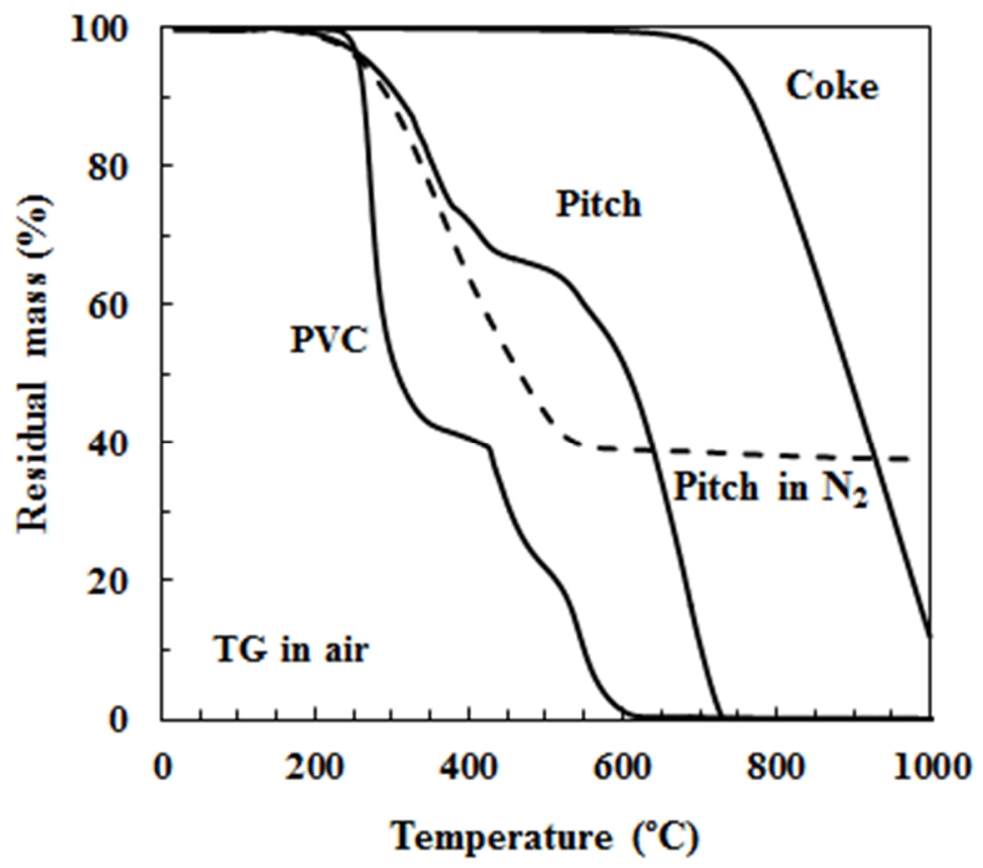

Fig. 6. The degradation of the coke, pitch and PVC in an air atmosphere. 


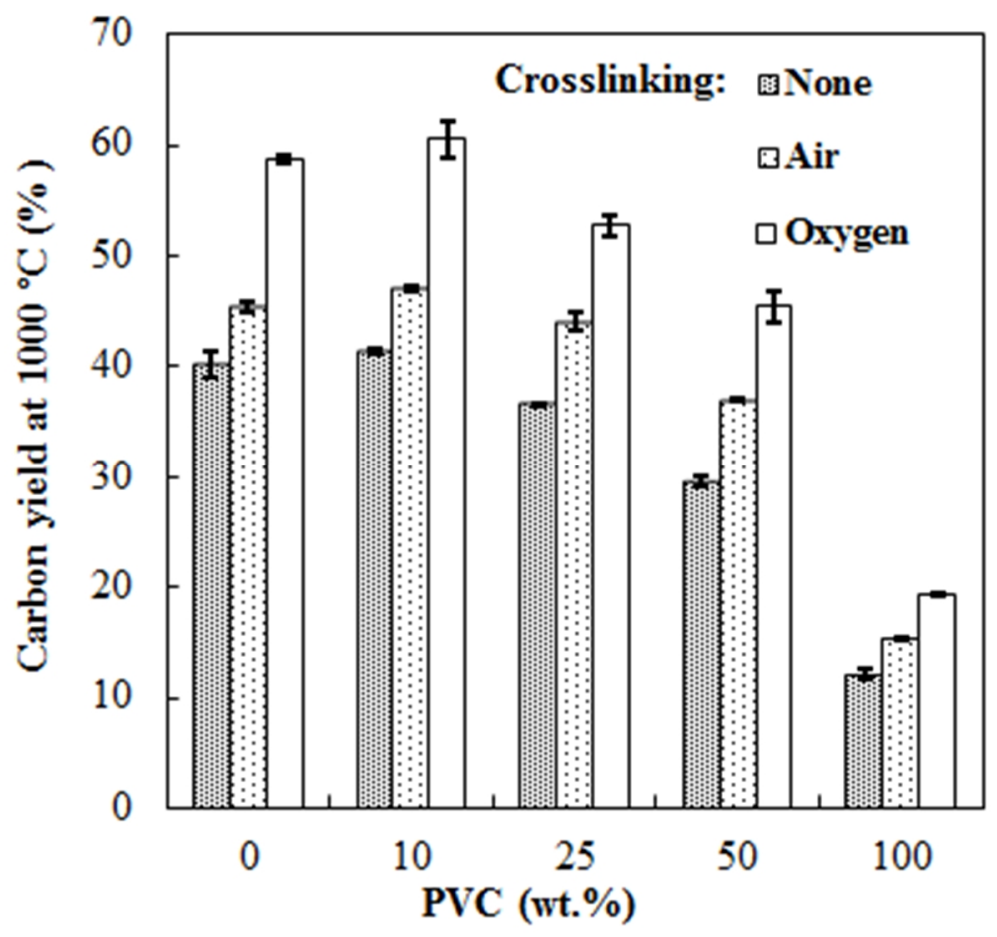

Fig. 7. The effect of thermal crosslinking on the carbon yield at $1000{ }^{\circ} \mathrm{C}$. Samples where heated in the TG to $400{ }^{\circ} \mathrm{C}$ in air or $\mathrm{O}_{2}\left(50 \mathrm{~mL} \cdot \mathrm{min}^{-1}\right)$, cooled to $25^{\circ} \mathrm{C}$ and then heated to $1000{ }^{\circ} \mathrm{C}$ at $10 \mathrm{~K} \cdot \mathrm{min}^{-1}$ in $\mathrm{N}_{2}$ flowing at $50.0 \mathrm{~mL} \cdot \mathrm{min}^{-1}$. The data are based on triplicate evaluations.

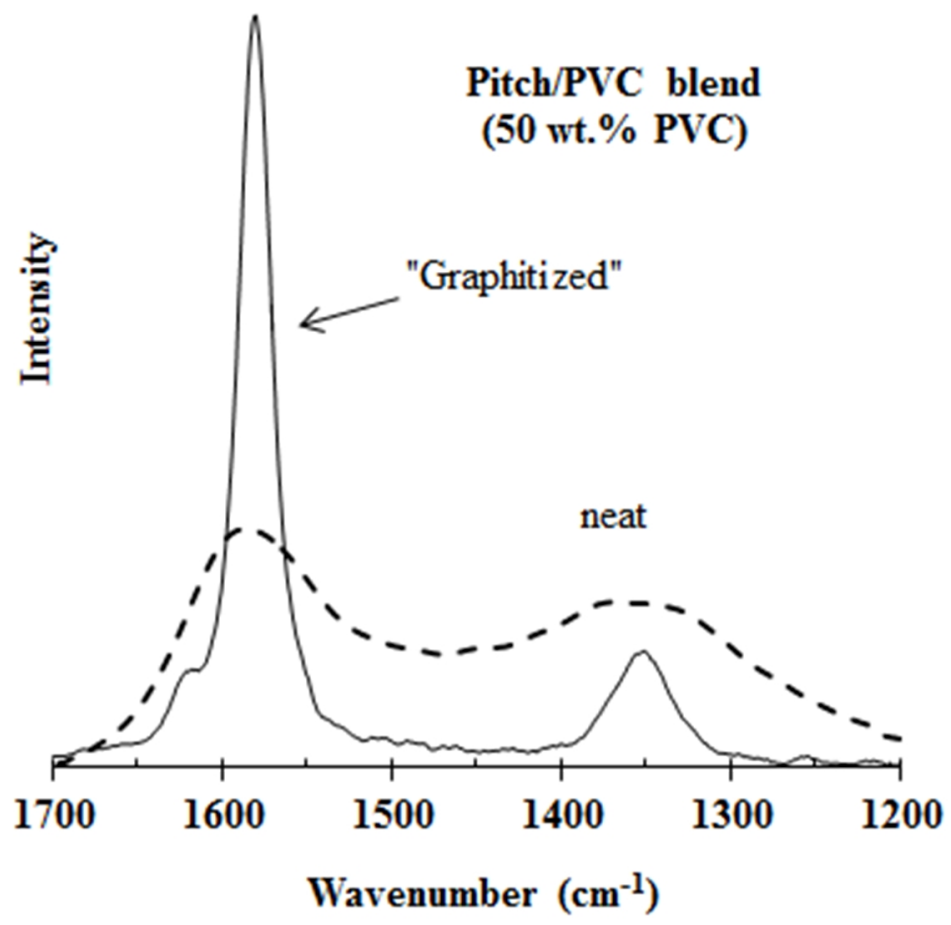

Fig. 8. Representative Raman spectra of a pitch/PVC 50/50 blend showing the effect of a "graphitizing" heat treatment $\left(1 \mathrm{~h}\right.$ at $\left.2400{ }^{\circ} \mathrm{C}\right)$. 


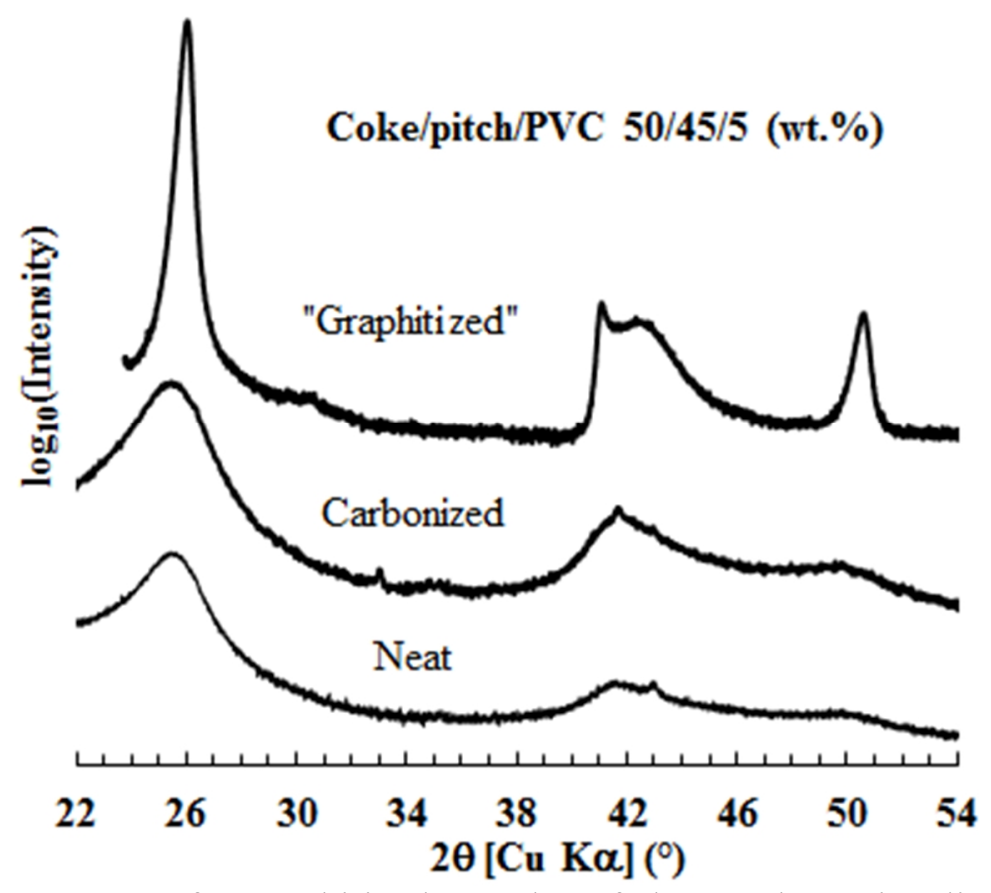

Fig. 9. XRD diffractograms for graphitized samples of electron beam irradiated pitch, PVC and their 50/50 blend.

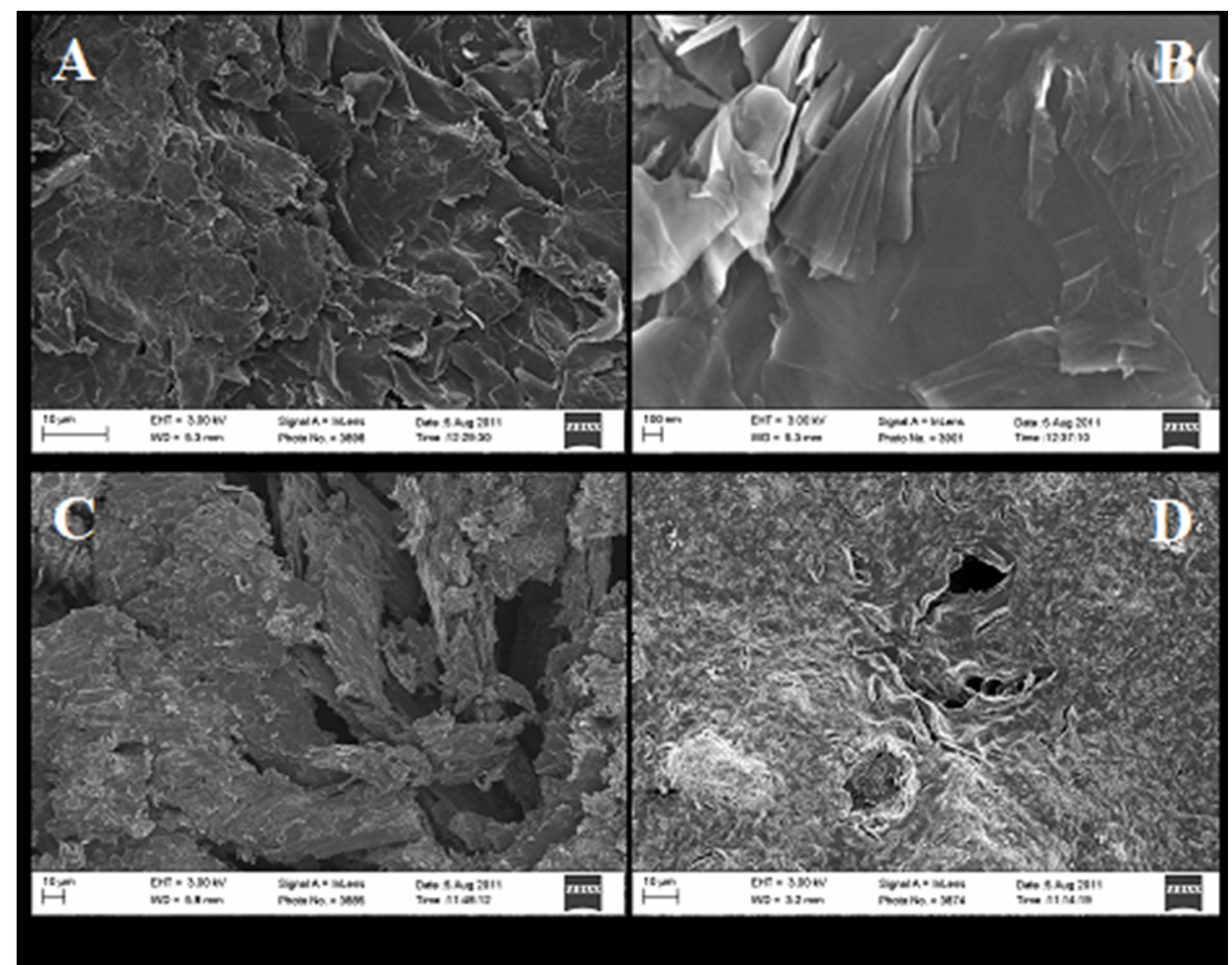

Fig. 10. FEG SEM pictures showing the morphology of "graphitized" samples: A \& B: Pitch; C: 50/50 pitch/PVC blend; D: 50/45/5 coke/pitch/PVC compound. 